\title{
Kepemilikan Manajerial, Kepemilikan Institusional dan Kebijakan Dividen serta Free Cash Flow sebagai Pemoderasi
}

\author{
Ni Made Ari Trisna Dewi ${ }^{1}$ \\ Fakultas Ekonomi dan Bisnis \\ Universitas Udayana, Indonesia
}

\section{Anak Agung Gde Putu Widanaputra2 \\ Fakultas Ekonomi dan Bisnis \\ Universitas Udayana, Indonesia}

\begin{abstract}
Surel : aritrisna1103@gmail.com
ABSTRAK

Penelitian ini bertujuan untuk mengetahui pengaruh kepemilikan manajerial dan kepemilikan institusional pada kebijakan dividen dengan free cash flow sebagai variabel moderasi pada perusahaan manufaktur yang terdaftar di Bursa Efek Indonesia (BEI) tahun 2015-2019. Pemilihan sampel melalui metode purposive sampling. 42 perusahaan dipilih sebagai sampel penelitian dengan 210 pengamatan. Teknik analisis yang digunakan ini adalah Moderated Regression Analysis (MRA). Hasil dari penelitian menunjukkan bahwa semakin tinggi kepemilikan manajerial maka semakin tinggi kebijakan dividen terutama pada perusahaan yang memiliki free cash flow yang tinggi, dan semakin tinggi kepemilikan institusional maka semakin tinggi kebijakan dividen terutama pada perusahaan yang memiliki free cash flow yang tinggi.
\end{abstract}

Kata Kunci: Kepemilikan Manajerial; Kepemilikan Institusional; Free Cash Flow; Kebijakan Dividen.

\section{Managerial Ownership, Institutional Ownership and Dividend Policy and Free Cash Flow as Moderator}

\begin{abstract}
This study aims to determine the effect of managerial ownership and institutional ownership on dividend policy with free cash flow as a moderating variable. This research was conducted at manufacturing companies listed on the Indonesia Stock Exchange (BEI) in 2015-2019. The sample was selected by means of a purposive sampling method with 42 companies as samples and 210 observations. The analysis technique used in this research is Moderated Regression Analysis (MRA). The results of this study indicate that the higher the managerial ownership, the higher the dividend policy, especially in companies that have high free cash flow, and the higher the institutional ownership, the higher the dividend policy, especially in companies with high free cash flow.
\end{abstract}

Keywords: $\quad$ Managerial Ownership; Institutional Ownership; Free Cash Flow; Dividend Policy.

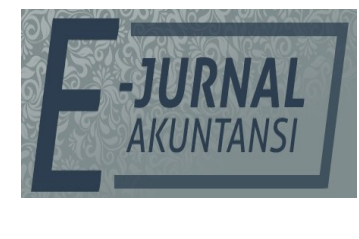

e-ISSN 2302-8556

Vol. 31 No. 7

Denpasar, Juli 2021

Hal. 1710-1719

DOI:

10.24843/EJA.2021.v31.i07.p08

PENGUTIPAN: Dewi, N.M.A.T., \&

Widanaputra, A.A.G.P.

(2021). Kepemilikan

Manajerial, Kepemilikan Institusional dan Kebijakan Dividen serta Free Cash Flow sebagai Pemoderasi. E-Jurnal Akuntansi, 31(7), 1710-1719

RIWAYAT ARTIKEL: Artikel Masuk: 1 Maret 2021 Artikel Diterima: 25 Mei 2021

Artikel dapat diakses : https://ojs.unud.ac.id/index.php/Akuntansi/index 


\section{PENDAHULUAN}

Perusahan dapat meningkatkan nilai perusahaan dengan peningkatan kinerja yang baik dimana dalam hal ini dilakukan melalui keputusan keuangan perusahaan. Keputusan keuangan tersebut meliputi: keputusan investasi, keputusan pendanaan, dan kebijakan dividen. Pembagian jumlah dividen bergantung pada aturan yang diterapkan perusahaan dan menjadi pertimbangan karena akan mempengaruhi pembiayaan invetasi di periode berikutnya. Makadari itu, perusahaan tentu mengoptimalkan kebijakan deviden dan mempertimbangkan faktor internal dan eksternal yang berpengaruh (Yasmita \& Widanaputra, 2018). Menurut Sari \& Budiasih (2016), kebijakan deviden dalam hal ini pembayaran dividen harus diperhatikan oleh manajemen karena bertujuan untuk mengurangi masalah keagenan dan kepentingan para pemegang saham dapat terpenuhi sehingga reputasi perusahaan dapat dipertahankan. Perusahaan harus memilih kebijakan dividen yang juga dapat memaksimalkan nilai perusahaan (Hauser \& Thornton, 2017). Pengaturan kas dan pengawasan oleh shareholder bertujuan untuk mencegah terjadi kesenjangan dan penggunaan kas untuk kepentingan pribadi oleh manajemen.

Menurut Giuli et al. (2020), Struktur kepemilikan perusahaan terjadi karena adanya perbandingan jumlah pemilik saham dalam perusahaan. Sebuah perusahaan dapat dimiliki oleh seseorang secara individu, masyarakat luas, pemerintah, pihak asing, maupun orang dalam perusahaan tersebut (manajerial). Kepemilikan bersama tersebut berpengaruh terhadap keuangan perusahaan yang terbatas pada aktivitas merger dan akuisisi. Kepemilikan manajerial merupakan salah satu aspek corporate governance yang dapat mengurangi timbulnya agency cost apabila porsinya dalam struktur kepemilikan di perusahaan ditingkatkan (Pujiati, 2015). Struktur keagenan perusahaan perlu dipertimbangkan untuk memperjelas hubungan antara kepemilikan manajerial dan kebijakan dividen sehingga tidak menimbulkan permasalahan antara pemegang saham dan manajer yang memutuskan kebijakan deviden (Kim et al., 2020). Kepemilikan saham oleh manajer akan meningkatkan motivasi manajer agar lebih berhati-hati dalam menetapkan kebijakan karena manajer turut menanggung konsekuensi dalam segala tindakan yang dilakukan (Mahariana \& Ramantha, 2014).

Kepemilikan institusional sebagai kepemilikan saham oleh pihak luar baik dalam bentuk institusi, lembaga atau kelompok lainnya (Widiastuti et al., 2013). Menurut Edison (2017), kepemilikan institusional adalah kepemilikan saham oleh pihak-pihak yang berbentuk institusi seperti yayasan, bank, perusahaan asuransi, perusahaan investasi, perusahaan berbentuk perseroan (PT), dan institusi lainnya. Semakin besar kepemilikan institusional maka akan semakin besar kekuatan dari institusi tersebut untuk mengawasi manajemen. Akibatnya, akan memberikan dorongan yang lebih besar kepada manajemen untuk mengoptimalkan kinerja perusahaan (Nisa, 2017).

Berdasarkan Andini \& Wirawati (2014), Faktor lain yang memengaruhi kebijakan dividen suatu perusahaan adalah free cash flow. Free cash flow adalah dana berlebih yang seharusnya disalurkan kepada para pemegang saham, berdasarkan kebijakan yang ditetapkan oleh manajer. Konflik keagenan dapat terjadi ketika perusahaan memperoleh arus kas bebas yang besar (Rossi et al., 2018). Dalam hal ini manajer ingin agar kas diinvetasikan pada asset perusahaan, namun pemegang 
saham ingin agar kas dibagikan menjadi dividen. Hal ini yang kemudian menimbulkan dugaan bahwa free cash flow berpengaruh terhadap pembayaran dividen perusahaan (Ngo et al., 2020). Pihak manajemen akan membatasi arus kas keluar berupa deviden dalam jumlah yang terlalu besar. Tujuan pembatasan ini untuk mempertahankan kelangsungan hidup perusahaan, menambah investasi, maupun melunasi utang (Jory et al., 2017). Free cash flow yang tinggi akan mempengaruhi kebijakan deviden yang ditetapkan oleh perusahaan. Berdasarkan teori keagenan, agency problem antara principal dan agent salah satunya terjadi karena pihak principal khawatir jika perusahaan memiliki free cash flow dalam jumlah besar akan digunakan untuk mengalokasikan pada sumber daya yang tidak efisien dan digunakan untuk melakukan investasi yang tidak menguntungkan (Chandra Dewi \& Putra, 2016).

Penelitian Sari \& Budiasih (2016) dan Sumartha (2018) menemukan bahwa kepemilikan manajerial berpengaruh positif pada kebijakan dividen. Namun pada penelitian yang dilakukan Yunisari \& Ratnadi (2018), Widiari \& Putra (2017); serta Al-Najjar (2016) menemukan bahwa kepemilikan manajerial berpengaruh negatif pada kebijakan dividen. Penelitian yang dilakukan Nugraheni \& Mertha (2019); Cao et al., (2017); Chang et al., (2016) menemukan bahwa kepemilikan institusional berpengaruh positif pada kebijakan dividen. Namun, hasil yang bertentangan diperoleh Widiari \& Putra (2017) serta penelitian Nisa (2017) yang menyatakan bahwa kepemilikan institusional bersifat negatif pada kebijakan dividen.

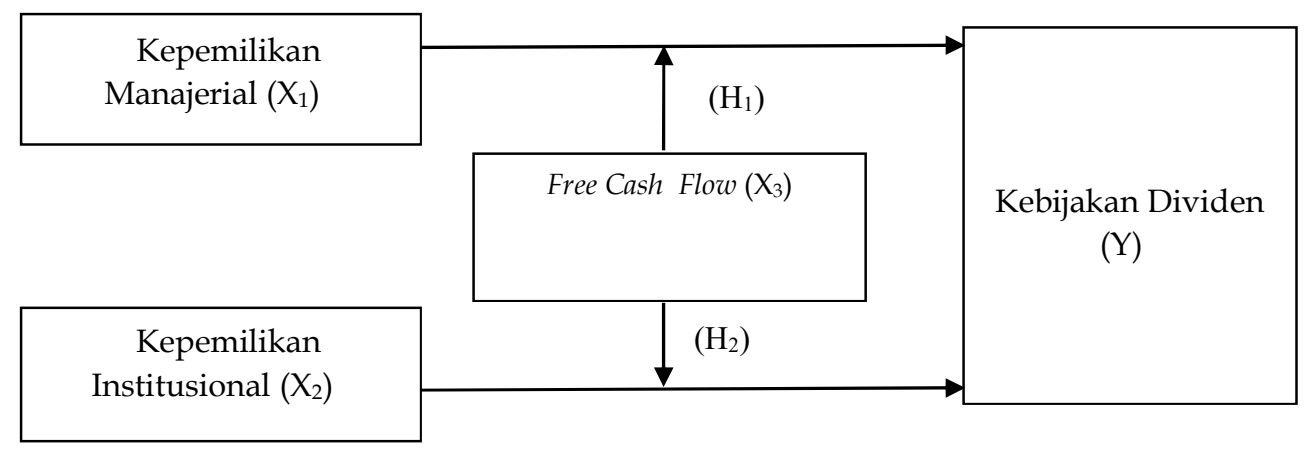

Sumber: Data Penelitian, 2021

\section{Gambar 1. Kerangka Konseptual}

Teori keagenan mengasumsikan bahwa semua individu bertindak atas kepentingan mereka sendiri. Principal menginginkan pengembalian yang sebesarbesarnya dan secepatnya atas investasi yang salah satunya dicerminkan dengan kenaikan porsi dividen dari tiap saham yang dimiliki (Thanatawee, 2011). Adanya kepemilikan manajerial dapat meminimalisir biaya agensi yang timbul dari adanya konflik keagenan (Dewi, 2008). Perusahaan yang memiliki free cash flow yang tinggi akan menyebabkan dividen yang dibagikan oleh perusahaan tidak terlalu rendah karena free cash flow merupakan dana berlebih di perusahaan yang seharusnya didistribusikan kepada para pemegang saham (Rosdini, 2010). Oleh karena itu, perusahaan akan membagikan free cash flow dalam bentuk dividen terutama ketika perusahaan memiliki free cash flow yang relatif tinggi (Thakur \& Kannadhasan, 2018). 
$\mathrm{H}_{1}$ : Semakin tinggi kepemilikan manajerial maka semakin tinggi kebijakan dividen terutama pada perusahaan yang memiliki free cash flow yang tinggi.

Berdasarkan teori agensi, biaya keagenan dapat diminimalkan dengan mekanisme pengawasan yang mensejajarkan kepentingan pemegang saham dengan manajer seperti melakukan pembagian kepada pemegang saham sehingga aliran kas bebas tidak disalagunakan oleh pihak internal (Kilincarslan \& Ozdemir, 2018). Kepemilikan institusional merupakan pemegang saham terbesar dalam perusahaan dibandingkan dengan kepemilikan lainnya (Guizani, 2018). Makadari itu pemegang saham dari pihak institusi berwenang melakukan kontrol dan mengawasi kinerja manajer untuk mengurangi masalah keagenan dan meningkatkan keuntungan, yang kemudian akan berdampak pada kebijakan deviden (Sakawa \& Watanabel, 2019). Adanya pembayaran dividen yang tinggi maka akan mengurangi biaya yang disebut dengan agency cost (Chang et al., 2016). Ketersediaan free cash flow yang memadai akan menghindari masalah agensi, serta pembagian deviden yang tidak terlalu rendah karena dihasilkan dari operasi bisnis yang sedang berjalan dan siap untuk dibagikan kepada pemegang saham tanpa mempengaruhi pertumbuhan perusahaan.

$\mathrm{H}_{2}$ : Semakin tinggi kepemilikan institusional maka semakin tinggi kebijakan dividen terutama pada perusahaan yang memiliki free cash flow yang tinggi.

\section{METODE PENELITIAN}

Pendekatan yang digunakan dalam penelitian ini adalah pendekatan kuantitatif berbentuk asosiatif yaitu penelitian yang bertujuan untuk mengetahui pengaruh ataupun juga hubungan antara dua variabel atau lebih (Sugiyono, 2019). Penelitian ini dilakukan pada perusahaan manufaktur di Bursa Efek Indonesia. Obyek penelitian ini adalah kebijakan dividen pada perusahaan manufaktur yang terdaftar di Bursa Efek Indonesia tahun 2015-2019. Penelitian ini menggunakan data kuantitatif berupa dividen yang diambil dari laporan keuangan pada perusahaan manufaktur yang terdaftar di Bursa Efek Indonesia. Populasi dalam penelitian ini adalah seluruh perusahaan manufaktur yang berjumlah 184 perusahaan yang terdaftar di BEI. Sampel dalam penelitian ini adalah 42 perusahaan manufaktur yang terdaftar di Bursa Efek Indonesia dari tahun 20152019 yang ditentukan dengan menggunakan teknik non probability sampling. Adapun metode pengumpulan data yang digunakan adalah metode observasi non partisipan. Teknik analisis yang digunakan adalah Moderated Regression Analysis (MRA) atau uji interaksi, dimana metode ini dilakukan dengan menambahkan variabel perkalian antara variabel bebas dengan variabel moderasinya (Ghozali, 2016). Model persamaan regresi dalam penelitian ini adalah sebagai berikut.

$$
Y=\alpha+\beta_{1} X_{1} X_{3}+\beta_{2} X_{2} X_{3}+\varepsilon
$$

\section{HASIL DAN PEMBAHASAN}

Statistik deskriptif digunakan untuk memberikan gambaran dari suatu data yang dilihat dari jumlah sampel, nilai minimum, nilai maksimum, nilai rata-rata (mean), dan deviasi standar (Std. devitiation) dari masing-masing variabel dalam penelitian tanpa adanya maksud untuk menarik kesimpulan (Ghozali, 2016). Hasil dari statistik deskriptif dapat dilihat pada Tabel 1, sebagai berikut. 
Tabel 1. Hasil Analisis Statistik Deskriptif

\begin{tabular}{llllll}
\hline Variabel & N & Minimum & Maksimum & $\begin{array}{l}\text { Rata- } \\
\text { rata }\end{array}$ & $\begin{array}{l}\text { Deviasi } \\
\text { Standar }\end{array}$ \\
\hline Kepemilikan manajerial & 210 & 0,00 & 0,81 & 0,028 & 0,102 \\
Kepemilikan institusional & 210 & 0,00 & 1,00 & 0,654 & 0,256 \\
Free cash flow & 210 & $-1,29$ & 0,36 & $-0,208$ & 0,252 \\
Kebijakan dividen & 210 & $-6,54$ & 23,18 & 0,817 & 2,290 \\
\hline
\end{tabular}

Sumber: Data Penelitian, 2021

Variabel kepemilikan manajerial yang berjumlah 210 sampel memiliki nilai minimum sebesar 0 dan nilai maksimum sebesar 0,81 pada PT Industri Jamu dan Farmasi Sido tahun 2015 dan 2016. Nilai rata-rata variabel kepemilikan manajerial sebesar 0,028 menunjukkan rata-rata kepemilikan manajerial dalam perusahaan sampel sebanyak 2,8 persen, dengan deviasi standar variabel kepemilikan manajerial sebesar 0,102. Variabel kepemilikan institusional yang berjumlah 210 sampel memiliki nilai minimum sebesar 0,00 pada PT. Vale Indonesia tahun 2019 dan nilai maksimum sebesar 1,00 pada PT Fajar Surya Wisesa tahun 2019. Nilai rata-rata variabel kepemilikan institusional sebesar 0,654 menunjukkan rata-rata kepemilikan institusional dalam perusahaan sampel sebanyak 65,4 persen, dengan nilai deviasi standar variabel kepemilikan institusional sebesar 0,256.

Variabel free cash flow yang berjumlah 210 sampel memiliki nilai minimum sebesar -1,29 pada PT Jembo Cable Company Tbk tahun 2019 dan nilai maksimum sebesar 0,36 pada PT Unilever Tbk tahun 2016. Nilai rata-rata variabel free cash flow sebesar 0,817 dengan nilai deviasi standar variabel free cash flow sebesar 0,252. Variabel kebijakan dividen yang berjumlah 210 sampel memiliki nilai minimum sebesar -6,54 pada PT Kimia Farma Tbk tahun 2019 dan nilai maksimum sebesar 23,18 pada PT Semen Baturaja Tbk tahun 2015. Nilai rata-rata variabel kebijakan dividen sebesar 0,817 dengan nilai deviasi standar variabel kebijakan dividen sebesar 2,290.

Model regresi akan lebih tepat digunakan dan menghasilkan perhitungan yang lebih akurat, apabila beberapa asumsi berikut dapat terpenuhi. Uji normalitas ini bertujuan untuk mengetahui apakah residual dari model regresi yang dibuat berdistribusi normal atau tidak, dengan menggunakan uji Kolmogorov-Smirnov.

Tabel 2. Hasil Uji Normalitas

\begin{tabular}{ll}
\hline & Unstandardized Residual \\
\hline $\mathrm{N}$ & 210 \\
Kolmogorov-Smirnov Z & 0,290 \\
Asymp. Sig. (2-tailed) & 0,081 \\
\hline
\end{tabular}

Sumber: Data Penelitian, 2021

Berdasarkan hasil pengujian diperoleh nilai signifikansi sebesar 0,081 yang lebih besar dari 0,05. Oleh karena nilai signifikansi uji Kolmogorov-Smirnov lebih dari 0,05 maka dapat disimpulkan bahwa data yang diuji berdistribusi normal.

Uji multikolinearitas bertujuan untuk menguji apakah dalam satu model regresi ditemukan adanya korelasi antar variabel bebas (Ghozali, 2016:105). Pengujian ini dilakukan dengan melihat nilai tolerance dan nilai Variance Inflation Factor (VIF). Jika nilai tolerance lebih dari 10 persen atau VIF kurang dari 10, maka 
DEWI, N.M.A.T., \& WIDANAPUTRA, A.A.G.P.

multikolinieritas dapat dilihat pada Tabel 3, sebagai berikut.

Tabel 3. Hasil Uji Multikolinearitas

\begin{tabular}{lll}
\hline \multirow{2}{*}{ Variabel } & \multicolumn{2}{l}{ Collinearity Statistic } \\
\cline { 2 - 3 } & Tolerance & VIF \\
\hline Kepemilikan manajerial $\left(\mathrm{X}_{1}\right)$ & 0,869 & 1,150 \\
Kepemilikan institusional $\left(\mathrm{X}_{2}\right)$ & 0,888 & 1,126 \\
Free cash flow $\left(\mathrm{X}_{3}\right)$ & 0,977 & 1,024 \\
\hline
\end{tabular}

Sumber: Data Penelitian, 2021

Hasil uji multikolinearitas menunjukkan bahwa variabel yang digunakan dalam penelitian memiliki nilai tolerance lebih besar dari 0,10 dan nilai VIF lebih kecil dari 10 sehingga dapat dinyatakan bahwa ketiga variabel bebas pada model regresi yang ada tidak terjadi gejala multikolinearitas.

Uji heterokedastisitas bertujuan menguji apakah dalam regresi terjadi ketidaksamaan varians dari residual satu pengamatan ke pengamatan yang lain (Ghozali, 2016: 139). Pengujian pada penelitian ini menggunakan Uji Glejser. Hasil uji heterokedastisitas untuk seluruh sampel disajikan dalam Tabel 4, sebagai berikut.

Tabel 4. Hasil Uji Heterokedastisitas

\begin{tabular}{cc}
\hline Variabel & Sig. \\
\hline Kepemilikan manajerial $\left(\mathrm{X}_{1}\right)$ & 0,084 \\
Kepemilikan institusional $\left(\mathrm{X}_{2}\right)$ & 0,081 \\
Free cash flow $\left(\mathrm{X}_{3}\right)$ & 0,198 \\
\hline
\end{tabular}

Sumber: Data Penelitian, 2021

Hasil uji heterokedastisitas menunjukkan nilai Sig. dari masing-masing variabel lebih besar dari 0,05 sehingga dapat disimpulkan bahwa variabel bebas pada model regresi yang ada, tidak terjadi gejala heteroskedastisitas.

Uji autokorelasi digunakan untuk mengetahui ada atau tidaknya korelasi antara kesalahan pengganggu pada periode $t$ dengan kesalahan pengganggu pada periode t-1 dalam model regresi yang diuji. Uji autokorelasi hanya dilakukan pada data time series (runtut waktu). Uji autokorelasi yang dilakukan dalam penelitian ini menggunakan uji Durbin-Watson. Hasil uji autokorelasi disajikan pada Tabel 5.

Tabel 5. Hasil Uji Autokorelasi

\begin{tabular}{llll}
\hline Model & $\mathrm{R}$ & $\mathrm{R}^{2}$ & Durbin-Watson \\
\hline 1 & 0,156 & 0,024 & 1,939 \\
\hline
\end{tabular}

Sumber: Data Penelitian, 2021

Berdasarkan hasil pengujian diperoleh nilai Durbin-Watson sebesar 1,939. Nilai du untuk jumlah sampel (N) sebanyak 210 dengan jumlah variabel bebas (k) sebanyak 3 adalah sebesar 1,754 maka nilai 4 -du yang didapat adalah 2,246. Hasil uji autokorelasi adalah $\mathrm{du}<\mathrm{dw}, 4$-du yaitu 1,754<1,939<2,246, maka dengan demikian tidak terjadi autokorelasi.

Penelitian ini menggunakan Moderated Regression Analysis (MRA) atau moderasi karena didalam persamaan regresinya mengandung unsur interaksi (perkalian dua atau lebih variabel independen). Hasil analisis dapat dilihat pada Tabel 6. 
Tabel 6. Hasil Uji Moderated Regression Analysis

\begin{tabular}{|c|c|c|c|c|c|c|}
\hline \multirow{2}{*}{\multicolumn{2}{|c|}{ Model }} & \multicolumn{2}{|c|}{$\begin{array}{l}\text { Unstandardized } \\
\text { Coefficients }\end{array}$} & \multirow{2}{*}{$\begin{array}{l}\text { Standardizert } \\
\text { Coefficient } \\
\text { Beta }\end{array}$} & \multirow[t]{2}{*}{$\mathrm{T}$} & \multirow[t]{2}{*}{ Sig } \\
\hline & & $B$ & Std.Erorr & & & \\
\hline \multirow[t]{6}{*}{1} & (Constant) & 0,715 & 0,196 & & 3,640 & 0,000 \\
\hline & $X 1 * X 3$ & 0,400 & 3,332 & 0,008 & 0,120 & 0,009 \\
\hline & $\mathrm{X} 2 * \mathrm{X} 3$ & 0,797 & 0,828 & 0,067 & 0,962 & 0,023 \\
\hline & Adjusted $R^{2}$ & & & & & 0,105 \\
\hline & F Hitung & & & & & 1,473 \\
\hline & Sig F & & & & & 0,002 \\
\hline
\end{tabular}

Sumber: Data Penelitian, 2021

Kebijakan Dividen $=0,715+0,400 X_{1}{ }^{*} X_{3}+0,797 X_{2}{ }^{*} X_{3}+\varepsilon$

Nilai koefisien variabel pemoderasi dengan model interaksi $\left(X_{1}^{*} X_{3}\right)$ bernilai positif sebesar 0,400 maka dapat disimpulkan bahwa apabila nilai interaksi kepemilikan manajerial dengan free cash flow $\left(\mathrm{X}_{1}{ }^{*} \mathrm{X}_{3}\right)$ bertambah satu satuan, maka nilai dari kebijakan dividen (Y) akan meningkat sebesar 0,400 satuan dengan asumsi variabel lainnya konstan. Nilai koefisien variabel pemoderasi dengan model interaksi $\left(\mathrm{X}_{2}{ }^{*} \mathrm{X}_{3}\right)$ bernilai positif sebesar 0,797 maka dapat disimpulkan bahwa apabila nilai interaksi kepemilikan institusional dengan free cash flow $\left(\mathrm{X}_{2}{ }^{*} \mathrm{X}_{3}\right)$ bertambah satu satuan, maka nilai dari kebijakan dividen (Y) akan meningkat sebesar 0,797 satuan dengan asumsi variabel lainnya konstan.

Koefisien determinasi pada model regresi dilihat dari Adjusted $\mathrm{R}^{2}$ sebesar 0,105 . Hal ini berarti bahwa variasi kebijakan dividen dapat dijelaskan sebesar 10,5 persen oleh interaksi free cash flow dengan variabel independen sedangkan sisanya 89,5 dipengaruhi oleh variabel lain yang tidak dijelaskan dalam penelitian ini. Hasil uji kelayakan model (Uji F) diperoleh nilai $F$ hitung sebesar 1,473 dengan signifikansi sebesar 0,002 lebih kecil dari 0,05. Jadi dapat disimpulkan bahwa model Moderated Regression Analysis (MRA) layak digunakan.

Hipotesis pertama $\left(\mathrm{H}_{1}\right)$ menyatakan bahwa semakin tinggi kepemilikan manajerial maka semakin tinggi kebijakan dividen terutama pada perusahaan yang memiliki free cash flow yang tinggi. Hasil pengujian hipotesis menunjukkan bahwa interaksi moderasi kepemilikan manajerial dengan free cash flow memiliki nilai sebesar 0,120 dengan nilai signifikansi sebesar 0,009 nilai ini lebih kecil dari 0,05 sehingga dapat disimpulkan bahwa hipotesis diterima. Sesuai dengan teori keagenan, masalah keagenan antara principal dan agent salah satunya terjadi karena pihak principal khawatir jika perusahaan memiliki free cash flow dalam jumlah besar akan digunakan untuk mengalokasikan pada sumber daya yang tidak efisien dan digunakan untuk melakukan investasi yang tidak menguntungkan. Adanya kepemilikan manajerial dapat meminimalisir biaya agensi yang timbul dari adanya konflik keagenan (Dewi, 2008). Apabila free cash flow perusahaan tinggi maka akan menghasilkan dividen yang tinggi pula. Hal ini dikarenakan perusahaan yang memiliki free cash flow tinggi akan berusaha menekan agency cost guna membuktikan bahwa arus kas bebas perusahaan tidak akan disalahgunakan oleh pihak internal. Perusahaan yang memiliki free cash flow yang tinggi akan menyebabkan dividen yang dibagikan oleh perusahaan tidak terlalu rendah karena free cash flow merupakan dana berlebih di perusahaan yang seharusnya didistribusikan kepada para pemegang saham (Rosdini, 2010). Oleh 
DEWI, N.M.A.T., \& WIDANAPUTRA, A.A.G.P. KEPEMILIKAN MANAJERIAL, KEPEMILIKAN...

karena itu, perusahaan akan membagikan free cash flow dalam bentuk dividen terutama ketika perusahaan memiliki free cash flow yang relatif tinggi. Hasil penelitian ini sesuai dengan hasil penelitian dari Widiari \& Putra (2017) yang menyatakan bahwa free cash flow memoderasi kepemilikan manajerial pada kebijakan dividen.

Hipotesis kedua $\left(\mathrm{H}_{2}\right)$ menyatakan bahwa semakin tinggi kepemilikan institusional maka semakin tinggi kebijakan dividen terutama pada perusahaan yang memiliki free cash flow yang tinggi. Hasil pengujian hipotesis menunjukkan bahwa interaksi moderasi kepemilikan institusional dengan free cash flow memiliki nilai sebesar 0,962 dengan nilai signifikansi sebesar 0,023 nilai ini lebih kecil dari 0,05 sehingga dapat disimpulkan hipotesis diterima. Hasil penelitian ini mendukung teori agensi, dimana peningkatan kepemilikan oleh investor institusional akan mampu meningkatkan mekanisme pengawasan terhadap manajemen yang mengelola penggunaan free cash flow sehingga dividen yang dibagikan tidak terlalu rendah. Dengan peningkatan mekanisme pengawasan oleh investor institusional maka para manajer akan lebih selektif dalam memilih alternatif investasi dan tidak hanya bertindak untuk mengejar keuntungan pribadi tetapi untuk meningkatkan nilai perusahaan dan kesejahteraan pemegang saham. Hasil penelitian ini sesuai dengan hasil penelitian dari Nisa (2017) yang menyatakan free cash flow memoderasi kepemilikan institusional pada kebijakan dividen. Perusahaan dengan free cash flow berlebih akan memiliki kinerja yang lebih baik dibandingkan perusahaan lainnya karena mereka dapat memperoleh keuntungan atas berbagai kesempatan yang mungkin tidak dapat diperoleh perusahaan lain. Peningkatan keuntungan ini akan berdampak pada peningkatan kebijakan dividen. Adanya pembayaran dividen yang tinggi maka akan mengurangi biaya yang disebut dengan agency cost (Chang et al., 2016).

\section{SIMPULAN}

Berdasarkan hasil penelitian dengan analisis data yang telah dilakukan maka dapat ditarik kesimpulan bahwa semakin tinggi kepemilikan manajerial maka semakin tinggi kebijakan dividen terutama pada perusahaan yang memiliki free cash flow yang tinggi. Hal ini berarti jika kepemilikan manajerial yang tinggi dalam perusahaan yang memiliki free cash flow yang tinggi akan menyebabkan dividen yang dibagikan oleh perusahaan tidak terlalu rendah. Semakin tinggi kepemilikan institusional maka semakin tinggi kebijakan dividen terutama pada perusahaan yang memiliki free cash flow yang tinggi. Hal ini berarti jika kepemilikan institusional yang tinggi dalam perusahaan maka akan mampu meningkatkan mekanisme pengawasan terhadap manajemen yang mengelola penggunaan free cash flow. Peneliti selanjutnya diharapkan agar dapat menambahkan variabel lain yang berpotensi memengaruhi kebijakan dividen seperti ukuran perusahaan. Peneliti menyarankan kepada perusahaan untuk mencermati pentingnya free cash flow, karena besar kecilnya free cash flow menunjukkan informasi mengenai kondisi dan kinerja keuangan perusahaan, serta para investor dan calon investor harus bijak dalam memutuskan investasi di suatu perusahaan dan mempertimbangkan posisi free cash flow perusahaan. 


\section{REFERENSI}

Al-Najjar, B., \& Kilincarslan, E. (2016). The effect of ownership structure on dividend policy: evidence from Turkey. Corporate Governance (Bingley), 16(1), 135-161. https:/ / doi.org/10.1108/CG-09-2015-0129

Cao, L., Du, Y., \& Ørding, J. (2017). Foreign institutional investors and dividend policy: Evidence from China. International Business Review, 26(5), 816-827. https://doi.org/10.1016/j.ibusrev.2017.02.001

Chang, K., Kang, E., \& Li, Y. (2016). Effect of institutional ownership on dividends: An agency-theory-based analysis. Journal of Business Research, 69(7), 25512559. https:// doi.org/10.1016/j.jbusres.2015.10.088

Dewi, S. C. (2008). Pengaruh Kepemilikan Managerial, Kepemilikan Institusional, Kebijakan Hutang, Profitabilitas Dan Ukuran Perusahaan Terhadap Kebijakan Dividen. 10(1), 47-58.

Edison, A. (2017). Struktur Kepemilikan Asing, Kepemilikan Institusional Dan Kepemilikan Manajerial Pengaruhnya Terhadap Luas Pengungkapan Corporate Social Responsibility (Csr). Bisma, 11(2), 164. https://doi.org/10.19184/bisma.v11i2.6311

Flow, F. C. (2011). Dividend Payout Ratio. SpringerReference, 4(1), 387-401. https://doi.org/10.1007/springerreference_1309

Gede, I. D., Mahariana, P., \& Ramantha, I. W. (2014). Pengaruh kepemilikan manajerial dan kepemilikan institusional terhadap manajemen laba. 3, 688-699.

Ghozali, H. I. (2016). Aplikasi Analisis Multivariate dengan Program IBM SPSS 23 (Edisi Kede). Badan Penerbit Universitas Diponegoro.

Ghozali, I. (2016). Aplikasi Analisis Multivariate dengan Program IBM SPSS 2.Edisi 8. In Semarang: Badan Penerbit Universitas Diponegoro.

Ghozali, Imam. (2016). Aplikasi Analisis Multivariete dengan Program (IBM. SPSS). In Aplikasi Analisis Multivariete dengan Program (IBM. SPSS). (8th ed.). Badan Penerbit Universitas Diponegoro.

Giuli, A. Di, Karmaziene, E., \& Sekerci, N. (2020). Common ownership and firm dividend policies. Finance Research Letters, 101779. https://doi.org/10.1016/j.frl.2020.101779

Guizani, M. (2018). The mediating effect of dividend payout on the relationship between internal governance and free cash flow. Corporate Governance (Bingley), 18(4), 748-770. https:// doi.org/10.1108/CG-01-2018-0011

Hauser, R., \& Thornton, J. H. (2017). Dividend policy and corporate valuation. Managerial Finance, 43(6), 663-678. https:/ / doi.org/10.1108/MF-05-2015-0157

Kilincarslan, E., \& Ozdemir, O. (2018). Institutional investment horizon and dividend policy: An empirical study of UK firms. Finance Research Letters, 24, 199-220. https:// doi.org/10.1016/j.frl.2017.09.016

Kim, W. S., Kiymaz, H., \& Oh, S. (2020). Jo 1 P. Pacific-Basin Finance Journal, 101457. https://doi.org/10.1016/j.pacfin.2020.101457

Linda Yasmita, N. P., \& Widanaputra, A. A. G. P. (2018). Pengaruh Asimetri Informasi Pada Kebijakan Dividen Dengan Investment Opportunity Set Sebagai Variabel Pemoderasi. E-Jurnal Akuntansi, 22, 2040. https://doi.org/10.24843/eja.2018.v22.i03.p15

Ngo, A., Duong, H., Nguyen, T., \& Nguyen, L. (2020). The effects of ownership structure on dividend policy: Evidence from seasoned equity offerings 
DEWI, N.M.A.T., \& WIDANAPUTRA, A.A.G.P.

(SEOs). Global Finance Journal, 44(2017), \#pagerange\#. https:// doi.org/10.1016/j.gfj.2018.06.002

Nijhof, Andre HJ Jeurissen, R. J. (2017). 기사 (Article) 와 안내문 (Information) [. The Eletronic Library, 34(1), 1-5.

Nisa, H. (2017). Pengaruh Kepemilikan Institusional dan Leverage Terhadap Kebijakan Dividen Dengan Free Cash Flow Sebagai Variabel Moderasi Pada Perusahaan Manufaktur di BEI Periode 2011-2015. JOM Fekon, 4(1), 387-401.

Nugraheni, N. P., \& Mertha, M. (2019). Pengaruh Likuiditas Dan Kepemilikan Institusional Terhadap Kebijakan Dividen Perusahaan Manufaktur. E-Jurnal Akuntansi, 26, 736. https://doi.org/10.24843/eja.2019.v26.i01.p27

Nyoman, N., \& Widiari, O. (2017). Pengaruh Kepemilikan Manajerial Dan Kepemilikan Institusional Pada Kebijakan Dividen Dengan Free Cash Flow Sebagai Pemoderasi. E-Jurnal Akuntansi, 20(3), 2303-2332.

Pranata, D., \& Pujiati, D. (2015). The effect of liquidity, profitability, sales growth, and dividend policy on stock prices after the implementation of IFRS. 5(2), 169-178. https:// doi.org/10.14414/tiar.v5i2.559

Purnama Sari, N., \& Budiasih, I. (2016). Pengaruh Kepemilikan Managerial, Kepemilikan Institusional, Free Cash Flow Dan Profitabilitas Pada Kebijakan Dividen. E-Jurnal Akuntansi, 15(3), 2439-2466.

Putra, I. W. (2017). Free Cash Flow Sebagai Pemoderasi Pengaruh Earnings Management Dan Kebijakan Dividen Pada Nilai Perusahaan. E-Jurnal Akuntansi, 0(0), 1259-1285.

Rosdini, D. (2010). Pengaruh Free Cash Flow terhadap Dividend Payout Ratio. Journal Accounting and Finance Universitas Padjajaran.

Rossi, F., Boylan, R., Cebula, R. J., Rossi, F., Boylan, R., \& Cebula, R. J. (2018). Financial decisions and ownership structure as control mechanisms of agency problems : evidence from Italy. https:/ / doi.org/10.1108/CG-01-2017-0014

Sakawa, H., \& Watanabel, N. (2019). Family control and ownership monitoring in Stakeholder-oriented corporate governance. Management Decision, 57(7), 1712-1728. https://doi.org/10.1108/MD-04-2018-0480

Sugiyono. (2019). Metode Penelitian Kuantitatif Kualitatif dan R\&D. In Metode Penelitian Kuantitatif Kualitatif dan RED. CV. Alfabeta.

Thanatawee, Y. (2011). Life-Cycle Theory and Free Cash Flow Hypothesis: Evidence from Dividend Policy in Thailand. International Journal of Financial Research, 2(2), 52-60. https:/ / doi.org/10.5430/ijfr.v2n2p52

Wayan, N., Andini, Lady, Gusti, N., \& Wirawati, P. (2014). Pengaruh Cash Flow Pada Kinerja Keuangan. 1, 107-121.

Widiastuti, Marselina, dkk. (2013). Dividend Policy and Foreign Ownership. In Jurnal Simposium Nasional Akuntansi XVI, (pp. 3401-3423).

Wuisan, F., Randa, F., \& Lukman, L. (2018). Pengaruh Struktur Kepemilikan Terhadap Kebijakan Dividen Perusahaan. Simak, 16(02), 119-141. https://doi.org/10.35129/simak.v16i02.39

Yunisari, N. W., \& Ratnadi, N. M. D. (2018). Pengaruh Profitabilitas dan Kepemilikan Manajerial Pada Kebijakan Dividen dengan Likuiditas Sebagai Variabel Moderasi. E-Jurnal Akuntansi, 23, 379. https://doi.org/10.24843/eja.2018.v23.i01.p15 